\title{
User-Generated Brands and Social Media: Couchsurfing and AirBnb
}

\author{
Natalia Yannopoulou \\ University of Newcastle \\ E-Mail: natalia.yannopoulou@newcastle.ac.uk \\ Mona Moufahim \\ University of Nottingham \\ E-Mail: Mona.Moufahim@nottingham.ac.uk \\ Xuemei Bian \\ University of Kent \\ E-Mail: X.M.Bian@kent.ac.uk
}

\begin{abstract}
The aim of this paper is to examine the brand identity construction of user-generated brands (UGBs), using discursive and visual analysis of UGBs' social media material in an attempt to contribute to a better understanding of this relatively new branding phenomenon. We specifically focused on two such brands: Airbnb and Couchsurfing. Our main findings reveal the emerged themes: the access to the private sphere, the human dimension and meaningful inter-personal discourses, and authenticity. The value of our research lies in identifying the specificities of the identity construction and visual representation of UGBs. Lastly, we offer practical suggestions and ideas for future research.
\end{abstract}

Keywords: User generated brands, User generated content, Social media, Discourse analysis

\section{INTRODUCTION}

Social media has reshaped the nature of marketing communications, as it has changed the way consumers interact with brands (Berthon, Pitt \& Campbell, 2008), and with each other, through concepts such as prosumers (Pitt et al, 2006) and counter 
and alter brand communities (Cova \& White, 2010). More importantly, it brings user-generated content and user-generated branding into the central focus of both researchers and practitioners. However, our knowledge of user-generated brands is still at a very early stage (Burmann, 2010). The aim of this paper is to examine the brand identity construction of user-generated brands (UGBs), using discursive and visual analysis of two such UGBs' social media material, in order to better understand them. Our main findings reveal three emerged themes of brand identify: the access to the private sphere, the human dimension and meaningful inter-personal discourses, and authenticity. The value of our research lies in identifying the specificities of the construction and visual representation of UGBs.

\section{USER-GENERATED BRANDS}

Brands are understood as "communicative objects that the brand manager wants consumers to buy into a symbolic universe as defined, in part, by the brand identity" (see Schroeder, 2009, P. 124). This traditional perspective fails to consider consumers' active involvement (Schroeder, 2009). In this paper, we are interested in a further development in consumers' involvement with brand meaning creation, through UGBs. User-generated branding is defined as "the strategic and operative management of brand related user-generated content to achieve brand goals" (see Burmann \& Arnhold, 2009, P. 66). The characteristics of UGBs identified to date can be summarized in the following. Co-creation of value becomes central, as the focus is on how to actively engage consumers and staff members in the same activities (Vargo \& Lusch, 2004). Individuals take upon a variety of roles, including that of producer, distributor, marketer and user of product (Pitt et al, 2006). In this way, resources are spread, while control is shared between users. UGBs foster a new lifestyle through collaborative consumption and peer-to-peer sharing economies. There is a noticeable shift towards the so-called 'exchange economy', with the introduction of numerous online brands, which allow consumers not only to purchase, but to also exchange products, services and skills. UGBs offer unique value to consumers with regard to identity formation and community building, that is not compromised by commercial motives, and thus can not be found in traditional brands (Hippel, Schroll \& Fuller, 2011). This in turn appropriates new indicators of success such as user engagement, value creation, transparency and authenticity. 


\section{METHODOLOGY: DISCURSIVE, THEMATIC AND VISUAL ANALYSIS}

For the analysis of the brand identity construction of UGBs, we employed discourse analysis, because through this methodology we are able to deconstruct our selected brands and appreciate how these organizations employ language, including text, images and any other significant semiotic events, to achieve certain effects (e.g. Blombäck \& Ramírez-Pasillas, 2012). In particular, we analysed text, pictorial and video images, from our chosen UGBs' websites and relevant material from their presence on social media. Our data selection culminated in the choice of two brands: Airbnb and CouchSurfing (CS), both specialising in accommodation for travellers, with Airbnb embedded in commerce, and CS based on free exchange. In our multi-layered analysis process, the 'surface' themes were first analysed as key representations of the organizations' espoused brand identity. However, we went beyond this level of analysis, and focused on the identification of the underlying discursive practices deployed by the organizations to create and represent themselves (Potter \& Wetherell, 1987), through social media, namely via members' interactions, and the co-consumption and co-production of the brand. We augmented this textual analysis with a consideration of the visual dimension of the brands (Schroeder, 2002). While, in total, over 170 online pages and 50 photographs and videos were analysed for both brands, the following section only presents the most salient research findings.

\section{FINDINGS}

\section{The Brand Users: Diversity vs. Generic Representations}

Core dimensions of the CS brand identity revolve around the notion of human relationships and cultural diversity. Visually, diversity and multiculturalism are represented through photographs and videos of CS surfers of both genders, from various ethnic backgrounds, and age groups. In the case of Airbnb, the brand narrative is based on people's stories captured by video and photographs. The website emphasizes the role of the host and puts forward the accommodation, thanks to high definition photographs, professionally shot. Such an approach is useful for the brand narrative, as it provides a visual representation of 'normal', 'typical' people putting a room in their homes for rent and allows a process of identification with and between members.

\section{The Social Dimension: Meaningful Inter-Personal Exchanges and Friendship}

A breakdown of the private and public sphere divide can be observed in both cases: people open up their private space and lives to complete strangers. This 
potentially emotional and psychologically difficult act is facilitated by the redefinition of 'stranger' as 'friend' within the CS community. This reframing is done via the detailed members' profiles. Surfers are also vouched for by other members. The relationship between members is (self-) defined along a 'friendship ranking', from CS friend, to best friends, including friend, good friend, and close friend. While the 'people' dimension is prominent across the different social media where the Airbnb brand is present, the emphasis is on the cities and the rooms available. In contrast with Couchsurfing, hosts can, but do not need to interact with guests. Nevertheless, the brand appears highly personalised. The 'testimonials' are a critical feature of the website, and help construct the brand as warm and human. Emotions also construct the Airbnb brand identity. We identified references to friendship, love, homeliness, and gift-giving. Both parties highlight the importance of a more meaningful life. Social media in this case become central, as consumers' profiles become part of the augmented product offering. This is because users refer to social media content as a valuable source of information and reliability regarding other users.

\section{The Collapse of the Private Sphere: Access and Authenticity}

The concepts of 'exchange', 'authenticity' and 'access' are at the core of both UGBs. Taking part in the brand experience provides a privileged access to a city and its people. By opening up their private homes, CS members provide a free space to stay, but would also typically take the surfer around, allowing their 'new friend' to explore the city, its culture, and people from the vantage point of a local resident: the ultimate authentic experience. Airbnb also contrasts its offering with more generic forms of travelling and accommodation in hotels. Experiencing a city and living like a local are valued and sought after by Airbnb users.

Authenticity is a valuable asset for brands (Schroeder, 2007). For the CS brand, authenticity is elicited by the brand experience itself, but also in its textual and visual expression within social media. Its written style and tone seem to adhere to the 'talking' style convention. One effect of such a style is the lack of formality and the removal of the distance between reader and writer. The bridging is furthered with the use of narratives, testimonials and anecdotes shared by members which represents a large part of the brand communications: these real personal and 'me-too' stories contribute to the creation of a strong sense of identification between the brand and the members. Users contribute to the content and visual construction of both brands: real members are filmed for the videos put on the websites. CS Offline activities (such as birthday parties and city raids) are also documented and shared through social media. 
Similarly to CS, the dimensions of innovativeness and authenticity are the key to Airbnb's identity. Given the commercial nature of the exchange, great care is taken in constructing an image of efficiency and professionalism. As such the brand presents many similarities with traditional ones. The link to the exchange economy is stressed. Again similarly to CS, the Airbnb brand exists through consumers. While the intervening 'hand' of Airbnb's managers is more visible than it is in CS, users do contribute to the creation of the brand value, meaning and identity, within the provided framework.

\section{DISCUSSION}

The introduction of Web 1.0 and 2.0 has changed the way consumers interact with brands, and most importantly the ways a brand can be created and managed by online communities (Burmann \& Arnhold, 2009). Although it is commonly accepted that UGB is rooted in the theoretical framework of the identity-based brand management approach (Burmann, Hegner \& Riley, 2009), little was known about how brand identity of UGBs is constructed until the present study.

In our discursive and visual analysis of CS and Airnbnb, we found references to a sustainability discourse and inter-personal exchange. This is unsurprising given that both organizations belong to the so-called collaborative consumption movement. While CS and Airbnb differ in terms of the exchange of money for accommodation, there are striking similarities between the two brands. Taking part in both brand experiences has been defined as significantly different to 'mainstream' consumption in terms of meaningful life enrichment, human contact, access and authenticity. Our analysis has also shown that both UGBs exist thanks to and through social media; both are produced, distributed, marketed, and consumed by users who infuse them with meaning and allow their existence on the ideological and physical levels. Users can also access the brands in different media, and contribute to a mesh of narratives that ultimately constitute a fluid brand identity. In addition, social media contribute to members' trust with one another, which is a critical feature for organizations within the exchange economy of trust. Practitioners could consult such brands, in order to discover new offerings and sources of consumer value. Future research should examine what makes UGBs successful, and how they are expected to evolve. Despite the interesting findings, this study has certain limitations, since it focuses on only two brands and the results could be partly related to the type of brands used in this study. 


\section{REFERENCES}

Berthon, P., Pitt, L., and Campbell, C. (2008). Ad Lib: When consumers create the ad. California Management Review, 50(4), http://dx.doi.org/10.2307/41166454.

Blombäck, A. and Ramírez-Pasillas, M. (2012). Exploring the logics of corporate brand identity formation. Corporate Communications: An International Journal, 17(1), 7-28. http://dx.doi.org/10.1108/13563281211196335.

Burmann, C. (2010). A Call for 'User-Generated Branding'. Journal of Brand Management, 18, 1-4. http://dx.doi.org/10.1057/bm.2010.30.

Burmann, C. and Arnhold, U. (2009). User Generated Branding: State of the Art of Research. Germany: Lit, Munster.

Burmann, C., Hegner, S., and Riley, N. (2009). Towards an identity-based branding. Marketing Theory, 9(1), 109-114. http://dx.doi.org/10.1177/1470593108100065.

Cova, B. and White, T. (2010). Counter-brand and alter-brand communities: the impact of Web 2.0 on tribal marketing approaches. Journal of Marketing Management, 26(3-4), 256-270. http://dx.doi.org/10.1080/02672570903566276.

Hippel, E., Schroll, R., and Fuller, J. (2011). Costless Creation of Strong Brands by User Communities: A Potential Challenge to Producer Profits. Retrieved, March, 15, 2012, from SSRN: http://ssrn.com/abstract=1756941 and http://dx.doi.org/10.2139/ssrn.

Pitt, L., Watson, R., Berthon, P., Wynn, D., and Zinkhan, G. (2006). The Penguin's Window: Corporate Brands from an Open-Source Perspective. Journal of the Academy of Marketing Science, 34(2), 115-127. http://dx.doi.org/10.1177/0092070305284972.

Potter, J. and Wetherell, M. (1987). Discourse and Social Psychology: Beyond Attitudes and Behaviour. London: Sage.

Schroeder, J. E. (2002). Visual Consumption. London: Routledge.

Schroeder, J. E. (2007). Visual Analysis of Images in Brand Culture. In Edward F. McQuarrie, Barbara J. Phillips (Eds.), Go Figure!: New Directions in Advertising Rhetoric (PP. 277-294). New York: M.E. Sharpe.

Schroeder, J. E. (2009). The cultural codes of branding. Marketing Theory, 9(1), 123-126. http://dx.doi.org/10.1177/1470593108100067.

Vargo, S. L. and Lusch, R. F. (2004). Evolving to a new dominant logic for marketing. Journal of Marketing, 68(1), 1-18. http://dx.doi.org/10.1509/jmkg.68.1.1.24036. 